\title{
Low Temperature Deposition of Metal Oxide Thin Films in Supercritical Carbon Dioxide using Metal-organic Precursors
}

Theodosia Gougousi, and Zhiying Chen

Physics, UMBC, 1000 Hilltop Circle, Baltimore, MD, 21250

\begin{abstract}
A novel chemical route in thin film formation that includes the use of inorganic and organic peroxides and metal organic complexes soluble in supercritical carbon dioxide has been investigated for the deposition of alumina, titania and zirconia thin films at low temperatures $\left(<150^{\circ} \mathrm{C}\right)$. The metal organic precursors used include: $\mathrm{Al}(\mathrm{acac})_{3}, \mathrm{OTi}(\mathrm{tmhd})_{2}$, and $\mathrm{Zr}(\mathrm{acac})_{4}$. Tert-butyl peroxide, and a 30\% aqueous solution of hydrogen peroxide were used as oxidants. Depositions were carried out in a $25 \mathrm{ml}$ hot wall reactor at pressures ranging from 2100 to 3900 psi at $80-140^{\circ} \mathrm{C}$. The deposited thin films were investigated by using X-ray photoelectron spectroscopy (XPS) and transmission Fourier transform infrared spectroscopy (FTIR). XPS and FTIR results indicate the formation of metal oxides thin films with some bonded carbon. The deposition temperatures achieved in this process are substantially lower than those used in conventional vacuum deposition techniques making feasible the deposition on temperature sensitive substrates and organic materials required for the development of hybrid organic/inorganic devices. Processing at low temperatures in supercritical carbon dioxide may provide the basis for the development of an alternative, environmentally friendly, thin film deposition technique for the processing of nanostructures.
\end{abstract}

\section{INTRODUCTION}

Metal oxide materials have many important applications, such as, gate oxides in Complimentary Metal Oxide Semiconductor (CMOS) devices, [1,2] magnetic tunnel junctions, [3] and optical coatings.[4] Conventional deposition techniques including chemical vapor or atomic layer deposition are chemical reaction based and are driven by the energy provided by a heated substrate. Both these vacuum-based techniques require relatively high substrate temperatures even when used in conjunction with plasma excitation, to assist in the precursor adsorption, oxidation and by-product desorption. [5] Use of solvation energy may provide a viable alternative for the deposition of thin films when high temperature processing is undesired. 
The use of solvation forces to assist in the chemical reaction on a substrate has already been applied to solvent based techniques such as electroplating, [6,7] electroless deposition, [8,9] and in supercritical carbon dioxide for the deposition of thin films. [10,11,12] Supercritical fluids have very intriguing properties: liquid-like density but gas-like transport properties, low viscosity, and high diffusivity. Additionally, they exhibit zero surface tension that allows diffusion in high aspect ratio trenches and microporous structures, and enhanced solvent ability near or above the critical point. In this project we use the enhanced solvent ability of supercritical $\mathrm{CO}_{2}$ to deliver large concentrations of metal organic precursor and oxidizers to a substrate, and make use of the energy provided by the solvation forces to complete the oxidation of the metal atom and the ligand removal at low temperature. Supercritical $\mathrm{CO}_{2}$ is safe to handle and exhibits easily accessible critical points (critical temperature $31^{\circ} \mathrm{C}$ and critical pressure 1070 psi). [13]

\section{EXPERIMENT}

The depositions were performed in a $\sim 25 \mathrm{ml}$ high-pressure stainless steel cell with sapphire windows purchased from Thar Technologies. A schematic of the reactor system is shown in Figure 1. Pressurized $\mathrm{CO}_{2}$ was delivered using an ISCO 260D syringe pump through a highpressure manifold. Resistive heaters with feedback control were used to maintain the temperature of the reaction cell within $\pm 1{ }^{\circ} \mathrm{C}$ of the set point value. Before each experiment, the cleaned cell was flushed with $\mathrm{CO}_{2}$ and a piece of $\mathrm{Si}$ was placed inside the cell along with approximately 20-30 $\mathrm{mg}$ of precursor. The cell was then sealed, heated to $45^{\circ} \mathrm{C}$ and pressurized with $\mathrm{CO}_{2}$ at $1250 \mathrm{psi}$. Then, the temperature was raised to the desired reaction temperature, and the precursor was observed to dissolve. The oxidizer solutions were introduced to the cell in two different ways: (1) loaded to the deposition cell in a quartz thimble simultaneously with the precursor; and (2) injected inside the deposition

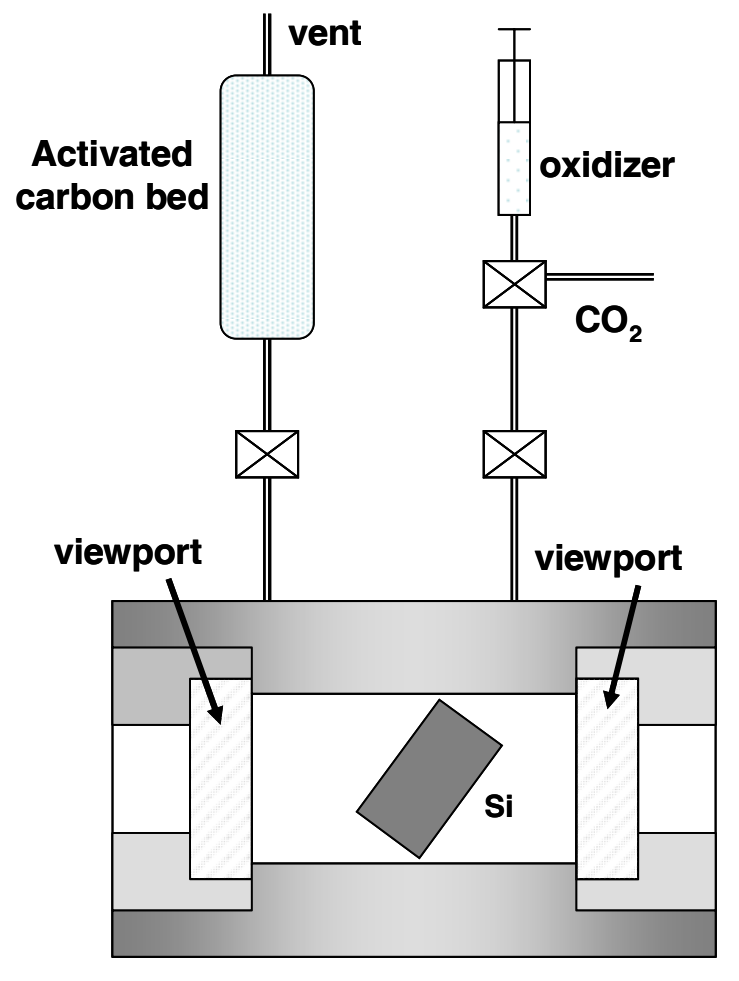

Figure 1. A schematic of the deposition system. 
cell after the temperature reached the desired reaction temperature. After a set reaction time (typically $30 \mathrm{~min}$ ), the cell was purged with $\mathrm{CO}_{2}$ and the effluent was filtered in an activated charcoal bed before venting. The samples were then rinsed in acetone in a sonic bath for $1 \mathrm{~min}$ to remove the precipitated precursor and reaction byproducts from the surface. The films were deposited on native oxide Si (100) surfaces. Precursors included aluminum acetylacetonate (99\%) $\left(\mathrm{Al}(\mathrm{acac})_{3}\right)$, zirconium acetylacetonate $(99 \%)\left(\mathrm{Zr}(\mathrm{acac})_{4}\right)$ and $\mathrm{Bis}(2,2,6$, tetramethyl-3,5heptane dionato) oxotitanium(IV) (OTi(tmhd) $)_{2}$ ) purchased from Strem Chemicals. All precursors were used as received. The precursors were stored in a well-sealed desiccator to prevent any reaction with ambient moisture. Coleman-grade $\mathrm{CO}_{2}$ with $99.99 \%$ purity was used for all the experiments. The oxidizers tested in the course of this work were: a $30 \%$ aqueous solution of hydrogen peroxide, and tert-butyl peroxide. The chemical structure of the precursors and tertbutyl peroxide is shown on Figure 2 .

The samples were characterized by X-ray photoelectron spectroscopy (XPS) and transmission Fourier transform infrared spectroscopy (FTIR). The XPS measurements were performed ex situ with a Kratos AXIS $165(\mathrm{Mg} \mathrm{K} \alpha, h \mathrm{v}=1253.6 \mathrm{eV}$, mono-chromatic X-ray source) at $90^{\circ}$ takeoff-angle at $0.5 \mathrm{eV}$ step size. A ThermoNicolet IR bench was used in the transmission mode. For each spectrum we collect 256 scans at $4 \mathrm{~cm}^{-1}$ resolution. The instrument was purged using purified air with low concentrations of moisture and $\mathrm{CO}_{2}$. A background

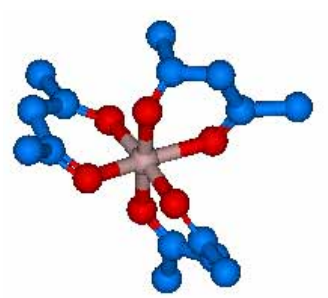

$\mathrm{Al}(\mathrm{acac})_{3}$

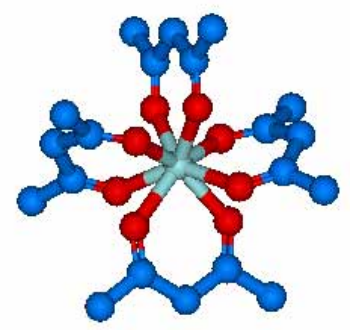

$\operatorname{Zr}(\mathrm{acac})_{4}$

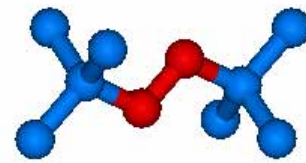

Tert butyl peroxide

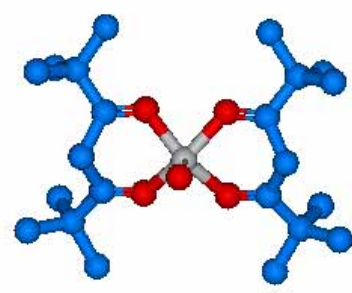

OTi(tmhd) $)_{2}$

Figure 2. A stick and ball model of the structure of the precursors and the organic peroxide used.

spectrum was collected after each measurement using a substrate fragment that originated from the same wafer as the deposited substrate.

\section{RESULTS}

Zirconium oxide films were deposited on $\mathrm{Si}$ substrates using $\mathrm{Zr}(\mathrm{acac})_{4}$ and tert-butyl peroxide at temperatures ranging from 120 to $140^{\circ} \mathrm{C}$ and pressures from 2100 to 3600 psi. The oxidizer was injected into the cell after the temperature reached the set point temperature. Figure $3 \mathrm{a}$ shows a survey XPS scan for a film deposited at $140^{\circ} \mathrm{C}, 3900 \mathrm{psi}$. The presence of $\mathrm{Zr}, \mathrm{O}$ 

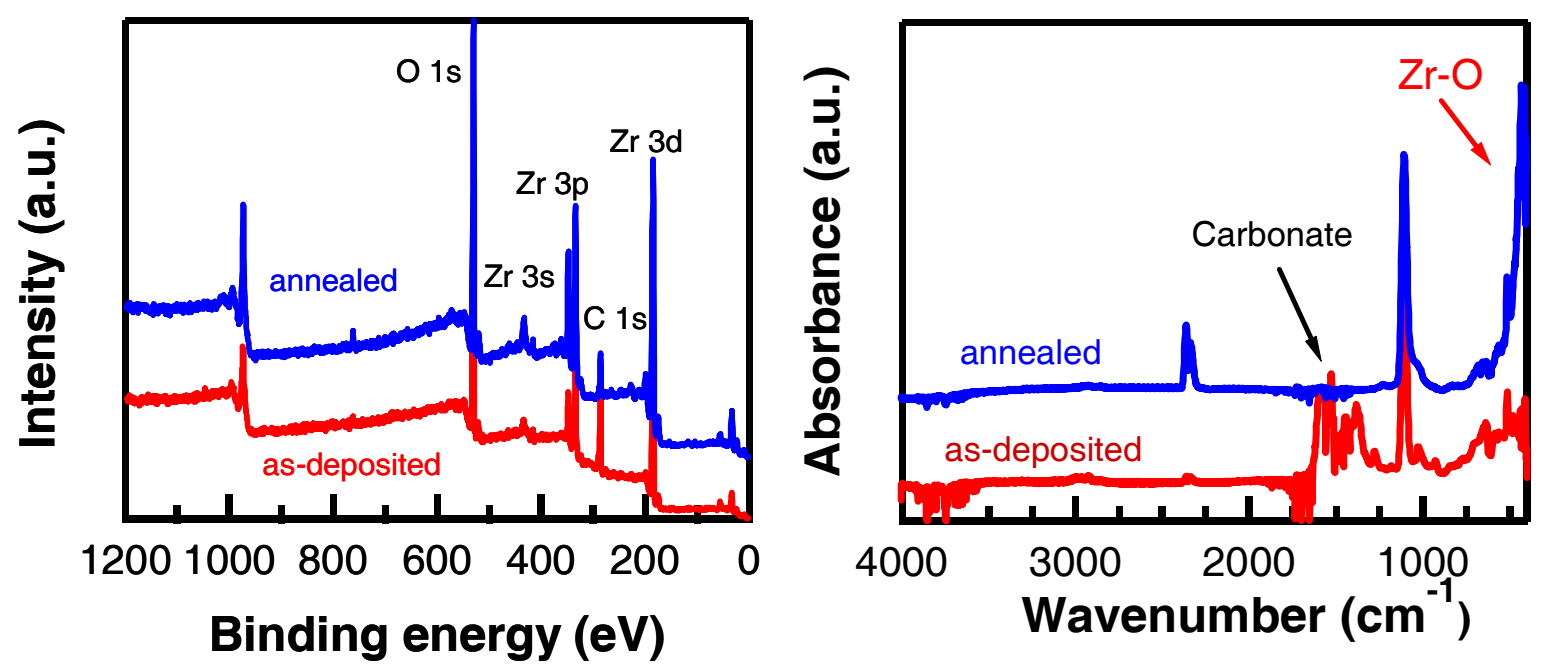

Figure 3. (a) XPS survey spectra for the as-deposited and annealed (4 min $700^{\circ} \mathrm{C}$ in $\mathrm{Ar}$ ) film from $\mathrm{Zr}(\mathrm{acac})_{4}$ and tert-butyl peroxide at $140^{\circ} \mathrm{C}(\mathrm{b})$ mid-IR spectra for the same films.

and $\mathrm{C}$ in the film is evident. Carbon is present in the film in two forms, adventitious carbon with a binding energy at $285.0 \mathrm{eV}$ that is due to surface contamination from the ambient, and bonded carbon in the form of carbonate species that has 3-5 eV chemical shift. Figure $3 \mathrm{~b}$ shows mid IR spectra for the same film. The formation of $\mathrm{ZrO}$ bonds is verified by the broad peak at 400-700 $\mathrm{cm}^{-1}$.[14] The absorptions in the $1200-1700 \mathrm{~cm}^{-1}$ range indicate the presence of carbonate type bonding in the film. [14] The infrared signature of the carbonate species practically disappears after anneals at $700^{\circ} \mathrm{C}$ in inert atmospheres.

Aluminum oxide films were deposited on $\mathrm{Si}$ substrates using $\mathrm{Al}(\mathrm{acac})_{3}$ and tert-butyl peroxide at temperatures ranging from 80 to $140^{\circ} \mathrm{C}$ and pressures from 2100 to 3600 psi. The oxidizer was injected into the cell after the temperature reached the set-point value. We
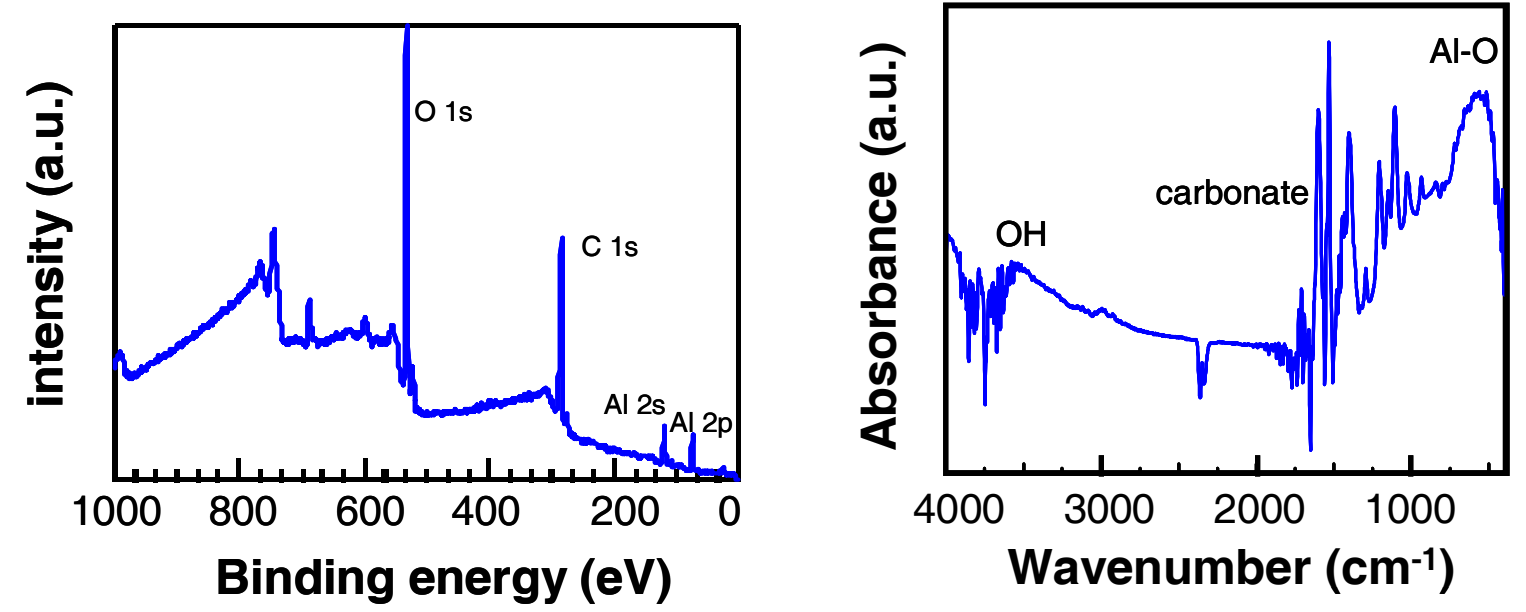

Figure 4. a) XPS survey spectrum for a film deposited from $\mathrm{Al}(\mathrm{acac})_{3}$ and tert-butyl peroxide at $110^{\circ} \mathrm{C}, 2900$ psi. b) mid-IR spectrum for the same film. 

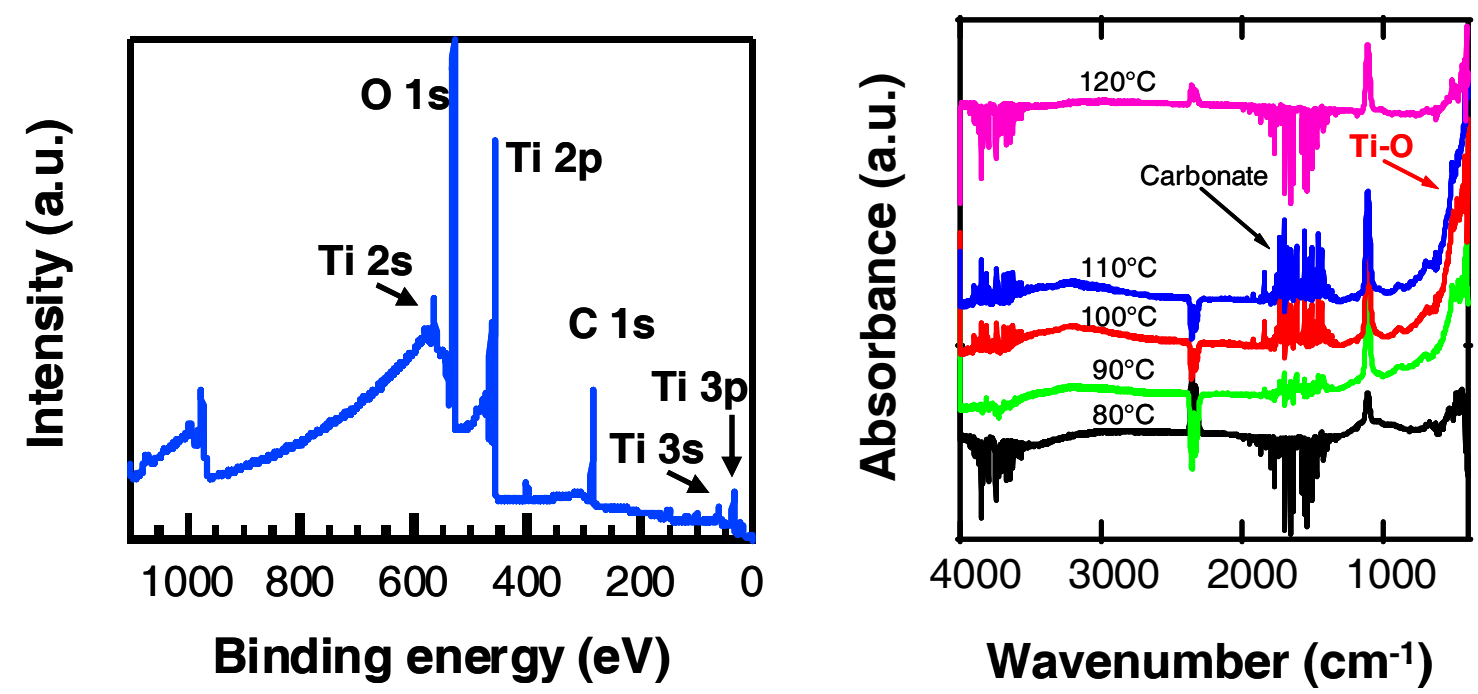

Figure 5. a)XPS survey spectrum for a film deposited from $\mathrm{OTi}(\mathrm{tmhd})_{2}$ and $\mathrm{H}_{2} \mathrm{O}_{2}$ at $110^{\circ} \mathrm{C}$, 2860 psi. b) mid-IR spectra for a series of films deposited at temperatures from $80-120^{\circ} \mathrm{C}$.

found a very narrow processing window for film formation at $110-120^{\circ} \mathrm{C}$. Figure $4 \mathrm{a}$ shows a survey XPS scan for a film deposited at $110^{\circ} \mathrm{C}$. The presence of $\mathrm{Al}, \mathrm{O}$ and $\mathrm{C}$ in the film is evident. Figure $4 \mathrm{~b}$ shows a mid IR spectrum for the same film. The formation of AlO bonds is verified by the broad peak at 400-900 $\mathrm{cm}^{-1}$. [15] Similarly to the $\mathrm{ZrO}_{2}$ films the infrared spectrum indicates the presence of carbonate type bonding in the film, disappears after mild anneals.

Titanium oxide films were deposited from the reaction of $\mathrm{OTi}(\mathrm{tmhd})_{2}$ and $\mathrm{H}_{2} \mathrm{O}_{2}$ in a broad temperature window ranging from 80 to $120^{\circ} \mathrm{C}$ and pressures around 3000 psi. The XPS spectrum verifies the presence of $\mathrm{Ti}, \mathrm{O}$, and some adventitious carbon in the thin film formation. This conclusion is corroborated by the IR spectra that show Ti-O absorptions.[16] For this material we observe only minimal carbonate formation, but there is some absorption in the 3600$3000 \mathrm{~cm}^{-1}$ range that is associated with the presence of $\mathrm{H}_{2} \mathrm{O}$ and $\mathrm{H}$-bonded $\mathrm{OH}$ in the film.

\section{CONCLUSIONS}

The formation of metal oxide thin films (alumina, zirconia, titania) thin films from the reaction of metal organic precursors with tert-butyl peroxide or hydrogen peroxide using supercritical carbon dioxide as the delivery medium has been demonstrated at temperatures below $140^{\circ} \mathrm{C}$, which is significantly lower than the temperature required for conventional chemical vapor deposition methods. Carbonate type impurities are detected in all films but they are desorbed after mild anneals. The process related carbon content of the film is difficult to analyze by ex-situ XPS due to the adventitious carbon from the environment, and post-deposition 
carbonate formation due to reactions of the film with atmospheric $\mathrm{CO}_{2}$. These results demonstrate the potential of the technique for low-temperature deposition of metal oxide thin films.

\section{ACKNOWLEDGMENTS}

Financial support from NSF (Grant: NER: CTS-0506690), from UMBC, and from the UMBC ADVANCE program is gratefully acknowledged.

\section{REFERENCES}

1. A. I. Kingon, J.-P. Maria, and S. K. Streiffer, Nature 406, 1032 (2000).

2. G. D. Wilk, R. M. Wallace, and J. M. Anthony, J. Appl. Phys. 89 (10), 5234 (2000).

3. J. M. DeTeresa, A. Barthelemy, A. Fert, J. P. Contour, F. Montaigne, and P. Sensor, Science 286, 507 (1999).

4. Q. Zhang, X. Li, J. Shen, G. Wu, J. Wang, and L. Chen, Materials Letter 45 (6), 311 (2000).

5. R. K. Waits, in "Thin film deposition and patterning" edited by H. G. Tompkins, (AVS, 1998).

6. W. M. Dubin, Microelectronic Engineering 70 (2), 461 (2003).

7. W. H. Li, J. H. Ye, and S. F. Y. Li, Journal of Applied Electrochemistry 31 (12), 1395 (2001).

8. T. P. Niesen, and M. R. De Guire, Journal of Electroceramics 6, 1697 (2001).

9. L. A. Porter, Jr., H. C. Choi, A. E. Ribbe, and J. M. Buriak, Nano-Letters 2 (10) 1067 (2002).

10. J. M. Blackburn, D. P. Long, and J. J. Watkins, Chemistry of Materials, 12 (9), 2625 (2000).

11. J. M. Blackburn, D. P. Long, A. Cabanas, and J. J. Watkins, Science 294, 141 (2001).

12. T. Gougousi, D. Barua, E. D. Young, and G. N. Parsons, Chem. Mater. 17, 5093 (2005).

13. M. McHugh and V. J. Krukonis, Supercritical Fluid Extraction (Butterworth-Heinemann, Boston, 1994).

14. B.-O. Cho, S. X. Lao, and J. P. Chang, J. Appl. Phys. 93, 9345 (2003).

15. P. Madhu Kumar, C. Balasubramanian, N.D. Sali, S.V. Bhoraskar, V.K. Rohatgi, and S. Badrinarayanan, Mater. Sci. Eng. B 1999, 63,215.

16. C. Pecharroman, F. Gracia, J. P. Holgado, M. Ocana, and A. R. Gonzalez-Elipe, J. Bassas, J. Santiso and A. Figueras, J. Appl. Phys. 93, 4634 (2003). 